\title{
The herbal medicine Cyperus amuricus inhibits proliferation of human hepatocellular carcinoma Hep3B cells by inducing apoptosis and arrest at the G0/G1 cell cycle phase
}

\author{
HAI HA THI PHAM ${ }^{*}$, YEONG-AE SEONG ${ }^{1 *}$, CHUL-WOONG OH ${ }^{2}$ and GUN-DO KIM ${ }^{1}$ \\ ${ }^{1}$ Department of Microbiology, College of Natural Sciences, and ${ }^{2}$ Department of Marine Biology, \\ College of Fisheries Sciences, Pukyong National University, Busan 48513, Republic of Korea
}

Received June 3, 2016; Accepted July 25, 2016

DOI: $10.3892 /$ ijo.2016.3698

\begin{abstract}
Cyperus amuricus (C. amuricus) is one of the most common herbs in Oriental folk medicine for exerting astringent, diuretic, wound healing and other intestinal problems. However, little is known about the molecular mechanism of $C$. amuricus on anticancer activity. In the present study, the underlying mechanism of the anticancer effect of $C$. amuricus were elucidated. The methyl alcohol extract from the whole plant of $C$. amuricus exhibited cytotoxicity against Hep3B cells, but not against A549 and $\mathrm{HaCaT}$ cells. Consistent with an acceleration of the sub-G1 phase, downregulation of cdc25A, cyclin D1 and cyclin E, CDK4 and 2 as well as E2F-1, phospho-Rb, with concomitant of upregulation of $\mathrm{p} 21^{\mathrm{CIP} 1 / \mathrm{WAF} 1}$, $\mathrm{p} 27^{\mathrm{KIPI}}$ and $\mathrm{p} 16^{\mathrm{INK} 4 \mathrm{a}}$ proteins, as evidenced by the appearance
\end{abstract}

Correspondence to: Professor Gun-Do Kim, Department of Microbiology, College of Natural Sciences, Pukyong National University, 45 Yongso-ro, Nam-Gu, Busan 48513, Republic of Korea E-mail: gundokim@pknu.ac.kr

Professor Chul-Woong Oh, Department of Marine Biology, College of Fisheries Sciences, Pukyong National University, 45 Yongso-ro, Nam-Gu, Busan 48513, Republic of Korea

E-mail: ohcw@pknu.ac.kr

*Contributed equally

Abbreviations: Apaf-1, apoptotic protease activating factor-1; C. amuricus, Cyperus amuricus; CDKIs, cyclin-dependent kinases inhibitors; CDKs, cyclin-dependent kinases; DAPI, 4',6-diamidino2-phenylindole; DFF, DNA fragmentation factor; DISC, death-inducing signaling complex; DMSO, dimethyl sulfoxide; ECL, enhanced chemiluminescent; FADD, Fas-associated death domain; FBS, fetal bovine serum; GAPDH, glyceraldehyde-3phosphate dehydrogenase; HCC, hepatocellular carcinoma; PARP, poly(ADP ribose) polymerase; PBS, phosphate-buffered saline; $\mathrm{Rb}$, retinoblastoma proteins; $\mathrm{tBid}$, truncated $\mathrm{Bid}$; $\mathrm{TNF}$, tumor necrosis factor; WST-1 ${ }^{\circledR}, 2$-(4-iodophenyl)-3-(4-nitrophenyl)-5-(2,4disulfophenyl)-2Htetrazolium, monosodium salt

Key words: Cyperus amuricus, cell cycle arrest, apoptosis, anticancer, Hep3B of cell cycle arrest, were detected in $C$. amuricus-treated Hep3B cells. Additionally, the sequential activation of various caspases (cleaved caspase- $8,-9,-3,-7$ and -6 , and cleaved PARP) and the changed expression of other proteins related to the apoptosis pathway were observed after $C$. amuricus exposure. An increment in the pro-apoptotic proteins (Bim, tBid, Bax and Bak) and a reduction of anti-apoptotic protein (Bcl-2) regulate Hep3B cell death by controlling the permeability of mitochondrial membranes and the release of cytochrome $c$ from mitochondria into the cytosol with Apaf-1 after $C$. amuricus treatment. This is the first study indicating the potential of $C$. amuricus as a complementary agent for prevention and treatment of human liver cancer.

\section{Introduction}

Cancers are a group of diseases characterized by uncontrolled cell growth and spread. Primary liver cancer, especially hepatocellular carcinoma (HCC), is the fifth most common malignancy with more than 500,000 new cases diagnosed every year, and the third leading cause of cancer death with a mortality-to-incidence ratio exceeding 0.9 in the world $(1,2)$. The rate of $\mathrm{HCC}$ is annually increasing worldwide between 3 and $9 \%$, and the incidence of HCC is particularly higher in Southeast Asia and sub-Saharan Africa due to the higher frequency of chronic viral hepatitis (3). Generally, HCC is associated with dietary aflatoxin B1 intake or heavy alcohol consumption, and alternative causes of hepatic cirrhosis with a persistent hepatitis $\mathrm{B}$ virus or $\mathrm{C}$ virus infection, which is a $3.2 \mathrm{~kb}$, partial dsDNA, non-cytopathic virus, and the most important etiologic factor for malignant HCC (4). Until now, although surgical resection, orthotropic liver transplantation, and radiofrequency ablation have shown excellent results in the treatment of early stage liver cancer, there is no curative therapy for patients with advanced HCC (2). Therefore, HCC remains a serious global problem, and more effective prevention, diagnosis and treatment strategies are urgently needed.

Apoptosis is linked to cell cycle arrest, and the blockade of the cell cycle is regarded as effective for eliminating cancer cells. In recent years, many chemotherapeutic agents have been shown to impart anti-proliferative effects via arrest of cell division at certain checkpoints in the cell cycle. The 
concept of cell cycle-mediated apoptosis has gained increasing attention as this pathway may provide minimal opportunity for acquired drug resistance, decreased mutagenesis and reduced toxicity $(5,6)$. These observations suggest new approaches could alter uncontrolled cancer cell growth by modulating cell cycle regulators causing cell cycle arrest and could be useful in prevention and/or intervention in human cancer (5).

Herbal medicines play an increasing role in primary health care systems among the population as synthetic anticancer remedies are beyond the reach of the common man due to the high cost and toxic side effects. Many plant-derived drugs have a vital role in cancer therapy which execute their therapeutic effects by inhibiting cancer activating enzymes and hormones, stimulating DNA repair mechanism, promoting production of protective enzymes inducing antioxidant action, killing tumors via programmed cell death and enhancing immunity (7). Cyperus amuricus (C. amuricus) is a monocotyledonous and multipurpose medicinal herb which belongs to Cyperaceae family. It is a perennial sedge with slender and scaly creeping rhizomes, fibrous base and arises singly from the triquetrous tubers with dense tuft of 10 to $60-\mathrm{cm}$. This delicate grass, growing in tropical, subtropical and temperate regions; is widespread in North America, Japan, Korea and Russia (Far East) (8). A few studies have been recently commissioned to elucidate the pharmacological activities of $C$. amuricus. The dried whole plant of this herb, well-known as Chinese Amuersuocao or Korean Bangdongsani, has been traditionally prescribed for exerting astringent, diuretic, diaphoretic, desiccant and cordial properties in folk medicine (9). Infusion of this grass has been commonly credited with treating wounds, tumors, piles and other intestinal problems in Bangladesh (10). Previous phytochemical investigation on $C$. amuricus revealed the presence of three antioxidant phenolic components, including 3,4-dimethoxy benzoic acid, 4-hydroxybenzoic acid, and piceatannol which exhibited powerful free radical scavenging, especially against DPPH and superoxide anions (11). The steam distillation of $C$. amuricus also showed $57.3 \%$ inhibitory activity of pancreatic lipase in vitro (12). However, there is no scientific report regarding the potential of $C$. amuricus in the prevention and treatment of cancer. Hence, the present study was conducted to elucidate the underlying mechanisms of the extract of $C$. amuricus-induced antiproliferation, cell cycle arrest, and apoptosis in HCC Hep3B cells in vitro, so as to supply scientific rationales for using $C$. amuricus as a new promising chemopreventive and/or chemotherapeutic agent against liver cancer.

\section{Materials and methods}

Cell culture and reagents. Hep3B (hepatocellular carcinoma), A549 (human lung adenocarcinoma) and HaCaT (noncancerous human keratinocyte) cells were purchased from the American Tissue Culture Collection (ATCC; Manassas, VA, USA). Cells were cultured in Dulbecco's modified Eagle's medium (DMEM) (for Hep3B and HaCaT), RPMI-1640 (for A549) (HyClone Laboratories, Logan, UT, USA) medium supplemented with $10 \%$ heat inactivated fetal bovine serum (FBS; HyClone Laboratories) and $1 \%$ penicillin-streptomycin (PAA Laboratories $\mathrm{GmbH}$, Pasching, Austria) at $37^{\circ} \mathrm{C}$ and $5 \%$ $\mathrm{CO}_{2}$. The methyl alcohol extract from the whole plant of $C$. amuricus (distribution number: 010-032) was obtained from the Korea Plant Extract Bank (KPEB, Cheongju, Korea) with the purity of $\geq 99.9 \%$, HPLC.

Cell viability assay. Exponential phases of Hep3B, A549 and HaCaT cells $\left(1 \times 10^{4}\right.$ cells/well) were seeded on 96-well plates (SPL Life Sciences, Gyeonggi, Korea) in triplicate. Following overnight incubation, cells were treated with various concentrations $(50,100,150$ and $200 \mu \mathrm{g} / \mathrm{ml})$ of an extracted fraction of $C$. amuricus and incubated for $24 \mathrm{~h}$. After the treatment, $10 \mu 1$ of EZ-Cytox Cell Viability Assay Solution WST- $1^{\circledR}$ (Daeil Lab Service, Seoul, Korea) was added to each well and incubated for an additional $3 \mathrm{~h}$. The absorbance of the reaction was measured using an ELISA reader (Molecular Devices, Sunnyvale, CA, USA) at $460 \mathrm{~nm}$ and cell viability was calculated. The cytotoxic activity of the extract was expressed as an $\mathrm{IC}_{50}$ value, which is the concentration of the extract that caused $50 \%$ cell death. The extract of $C$. amuricus with an $\mathrm{IC}_{50}$ value $\leq 150 \mu \mathrm{g} / \mathrm{ml}$ was considered active on Hep3B cells. Dimethyl sulfoxide (DMSO; Sigma-Aldrich, St. Louis, MO, USA) was used to dilute the extract and the final concentration of DMSO in each well was not in excess of $0.05 \%(\mathrm{v} / \mathrm{v})$. No adverse effect due to the presence of DMSO was observed.

Treatment of Z-VAD-fmk. Hep3B cells were divided into four groups to compare caspase-dependent and caspaseindependent cell death as follows: non-treated, Z-VAD-fmk (pan-caspase inhibitor; Sigma-Aldrich), C. amuricus, and C. amuricus with Z-VAD-fmk groups. After $24 \mathrm{~h}$, the cells were transferred to a fresh medium containing no agent (control group), Z-VAD-fmk (50 $\mu \mathrm{M}$ Z-VAD-fmk), C. amuricus $(150 \mu \mathrm{g} / \mathrm{ml} \mathrm{C}$. amuricus $)$, or a combination (150 $\mu \mathrm{g} / \mathrm{ml} \mathrm{C.} \mathrm{amuricus} \mathrm{and} 50 \mu \mathrm{M} \mathrm{Z-VAD-fmk).} \mathrm{After}$ treatment for $24 \mathrm{~h}, 10 \mu \mathrm{l}$ of WST-1 solution was added to each well, further incubated for $3 \mathrm{~h}$, and then cell viability was measured at $460 \mathrm{~nm}$ using an ELISA reader.

DAPI staining. Hep3B cells were treated with the concentration of 100,150 and $200 \mu \mathrm{g} / \mathrm{ml}$ of the $C$. amuricus extract for $24 \mathrm{~h}$. The cells were rinsed once with phosphate-buffered saline (PBS) buffer (135 mM sodium chloride, $2.7 \mathrm{mM}$ potassium chloride, $4.3 \mathrm{mM}$ sodium phosphate, $1.4 \mathrm{mM}$ potassium dihydrogen phosphate) and stained by addition of $1 \mu \mathrm{g} / \mathrm{ml}$ DAPI solution (Roche Applied Science, Indianapolis, IN, USA) in methanol (Sigma-Aldrich). After incubation in the dark at $37^{\circ} \mathrm{C}$ for $20 \mathrm{~min}$, cells were washed twice with PBS buffer, and then fixed with $4 \%$ formaldehyde (Junsei, Tokyo, Japan) for $15 \mathrm{~min}$. The nuclear morphology of the cells was observed under a Laser Scanning Confocal microscope (Carl Zeiss LSM 700; Carl Zeiss, Oberkochen, Germany).

DNA fragmentation. For detecting genomic DNA fragmentation, the treated Hep3B cells were washed with ice-cold PBS buffer and harvested. The collected cells were handled by following the protocol of DNeasy ${ }^{\circledR}$ Blood and Tissue kit (Qiagen GmbH, Hilden, Germany). The isolated DNA was separated in a $1.5 \%$ agarose gel (Life Technologies Inc., Grand Island, NY, USA) and visualized by ethidium bromide staining (Sigma-Aldrich) under a UV transilluminator (Vilber Lourmat, Marne-la-Vallee, France). 
A

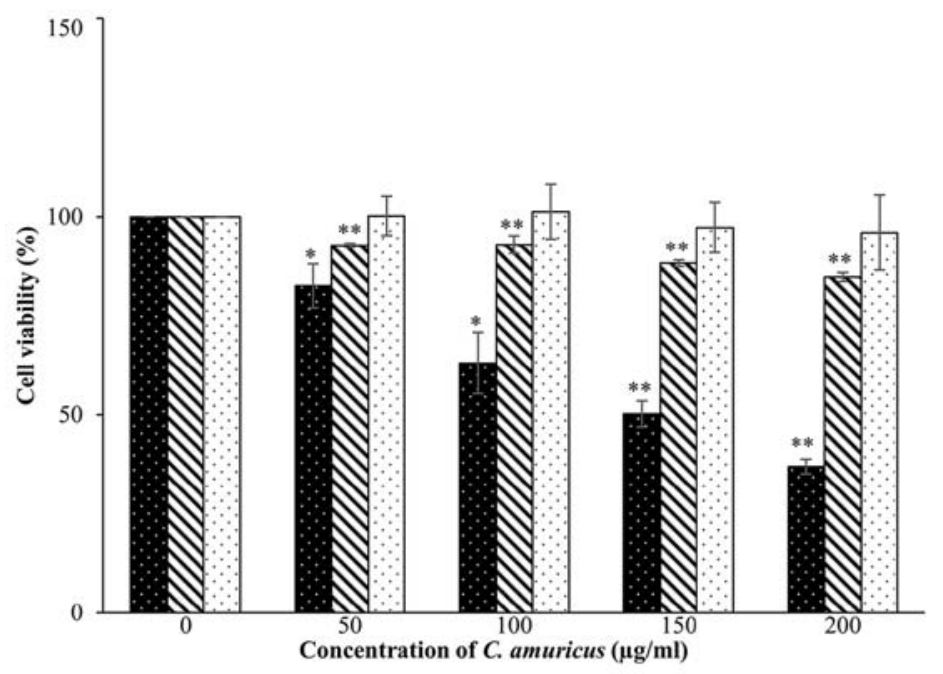

- Hep3B

ه A549

$\square \mathrm{HaCaT}$
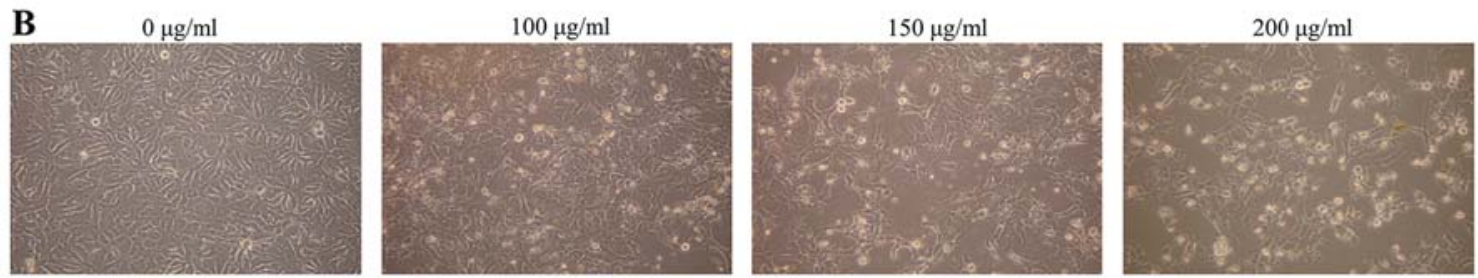

Figure 1. Effects of C. amuricus on cell viability of Hep3B cells. (A) Cytotoxicity of the C. amuricus extract was determined using the cell viability assay Hep3B, A549 and HaCaT cells were treated with 50-200 $\mu \mathrm{g} / \mathrm{ml}$ of the extract for $24 \mathrm{~h}$. Bars represent the mean $\pm \mathrm{SD}$ of three experiments. ${ }^{*} \mathrm{P}<0.05$; ${ }^{* *} \mathrm{P}<0.01$. (B) Morphological features of apoptosis in Hep3B cells after the C. amuricus exposure. Hep3B cells were incubated with the extract for the indicated concentrations and visualized by the inverted microscope (magnification, $\mathrm{x} 100)$.

Cell cycle analysis. Briefly, Hep3B cells were harvested by trypsinization and fixed with $70 \%$ ethanol overnight at $4^{\circ} \mathrm{C}$. Then, the cells were resuspended in PBS buffer containing $0.2 \mathrm{mg} / \mathrm{ml} \mathrm{RNase}$ and incubated for $1 \mathrm{~h}$ at $37^{\circ} \mathrm{C}$. The cells were stained with $40 \mu \mathrm{g} / \mathrm{ml}$ propidium iodide (Sigma-Aldrich) at room temperature for $30 \mathrm{~min}$ in the dark. The cell cycle was analyzed based on DNA contents using a flow cytometer (Becton-Dickinson, Mountain View, CA, USA).

Protein extraction and western blot analysis. Hep3B cells were washed once with PBS buffer and then lysed by the addition of lysis buffer [(50 mM Tris-Cl (pH 7.5), $150 \mathrm{mM} \mathrm{NaCl}$, $1 \mathrm{mM}$ DTT, $0.5 \%$ NP-40, $1 \%$ Triton X-100, $1 \%$ Deoxycholate, $0.1 \%$ SDS and proteinase inhibitors (PMSF, EDTA, aprotinin, leupeptin and prostatin A)] (Intron Biotechnology, Gyeonggi, Korea). After $30 \mathrm{~min}$ on ice, lysates were collected and clarified by centrifugation at $14,000 \mathrm{rpm}$ for $20 \mathrm{~min}$ at $4^{\circ} \mathrm{C}$. Cytosolic fractions were prepared using NE-PER ${ }^{\circledR}$ Nuclear and Cytoplasmic Extraction reagents (Thermo Fisher Scientific, Rockford, IL, USA) according to the manufacturer's protocol. Aliquots of whole cell lysates or cytosolic fractions were subjected to $10 \%$ SDS-PAGE and then transferred to a nitrocellulose membrane (Pall Corp., Pensacola, FL, USA). The membranes were blocked with 5\% skim milk in PBST (PBS buffer and 0.5\% Tween-20). After blocking non-specific sites, the membranes were probed with primary antibodies (Cell Signaling Technology, Inc., Danvers, MA, USA) and then washed in PBST three times, followed by incubation for $1 \mathrm{~h}$ with horseradish peroxidase-conjugated anti-rabbit IgG or antimouse $\operatorname{IgG}$ as second antibodies (Cell Signaling Technology). The blots were then washed in PBST and visualized by an enhanced chemiluminescent (ECL) detection solution (Pierce, Rockford, IL, USA). Anti-Bim was obtained from Santa Cruz Biotechnology (Santa Cruz, CA, USA). All other antibodies were purchased from Cell Signaling Technology.

Statistical analysis. Determinations were performed in triplicate and the results are presented as mean $\pm \mathrm{SD}$. Differences between groups were analyzed by one or two way ANOVA, followed by Fisher's protected least-significant difference. $\mathrm{P}<0.05$ was considered as statistical significance $\left({ }^{*} \mathrm{P}<0.05\right.$; ${ }^{* *} \mathrm{P}<0.01$ in the figures).

\section{Results}

Effects of C. amuricus on cell growth. In order to understand the cytotoxicity of the extract, Hep3B, A549 and HaCaT cells were exposed to the methanol extract of $C$. amuricus by cell viability assay. As shown in Fig. 1A, the $C$. amuricus extract did not have significant effects on either A549 or HaCaT cell viability while the extract (over $100 \mu \mathrm{g} / \mathrm{ml}$ ) caused remarkable growth inhibition and a marked decrease in cell viability only in Hep3B cells. Cell death reached $50 \%$ with $150 \mu \mathrm{g} / \mathrm{ml}\left(\mathrm{IC}_{50}\right)$ and $63 \%$ with $200 \mu \mathrm{g} / \mathrm{ml}$ of the C. amuricus treatment for $24 \mathrm{~h}$, respectively, and those concentrations were used in subsequent experiments to investigate the mechanism of cell death. Additionally, morphological changes of Hep3B cells treated with or without the extract of $C$. amuricus for $24 \mathrm{~h}$ were visualized under the inverted microscope (magnification, x100). Compared with the non-treated cells, most of the C.amuricustreated Hep3B cells (100-200 $\mu \mathrm{g} / \mathrm{ml}$ of the extract) did exhibit morphological features of apoptosis, such as cell membrane 


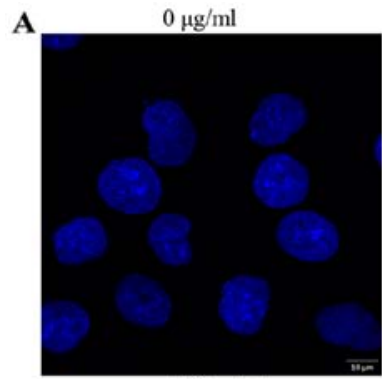

$150 \mu \mathrm{g} / \mathrm{ml}$

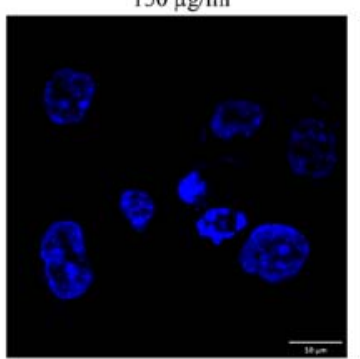

$100 \mu \mathrm{g} / \mathrm{ml}$

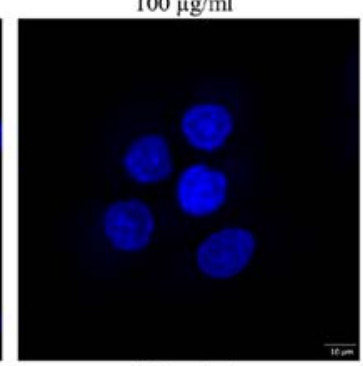

$200 \mu \mathrm{g} / \mathrm{ml}$

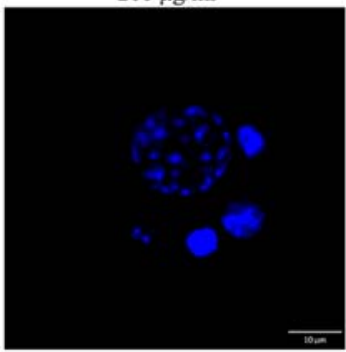

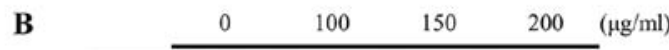

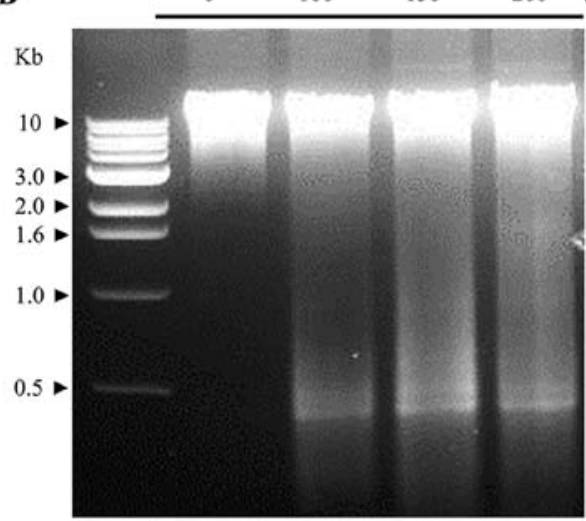

Figure 2. Effects of $C$. amuricus on the induction of apoptosis of Hep3B cells. Cells were treated with the extract of $C$. amuricus for the indicated concentrations for $24 \mathrm{~h}$. (A) DAPI staining: the cells containing condensed chromatin or exhibiting fragmented nuclei were identified as apoptotic bodies (magnification $\mathrm{x} 1,000)$. (B) Genomic DNA fragmentation: the isolated DNA from the treated cells was analyzed on a $1.5 \%$ agarose gel with $10 \mathrm{~kb}$ DNA ladder.
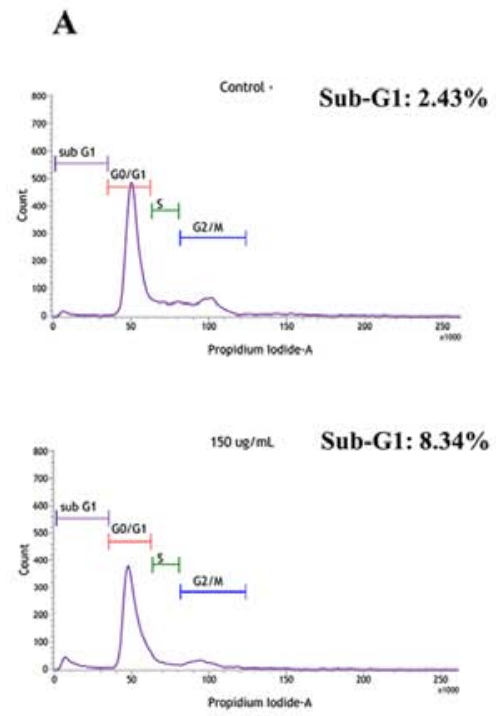
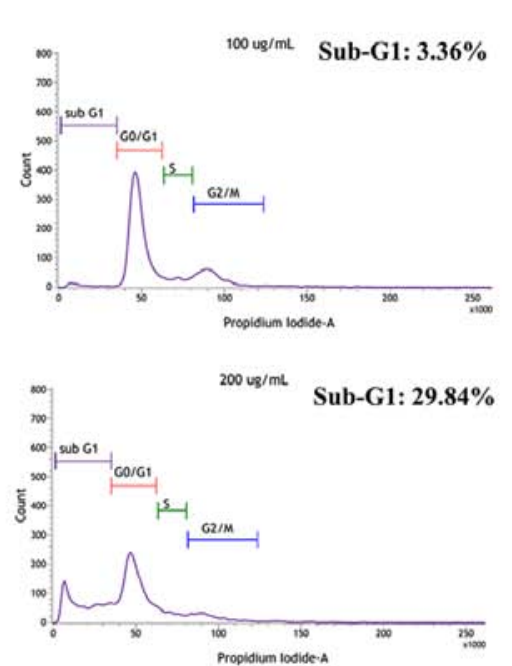

E2F-1

Phospho Rb (Ser780)

GAPDH

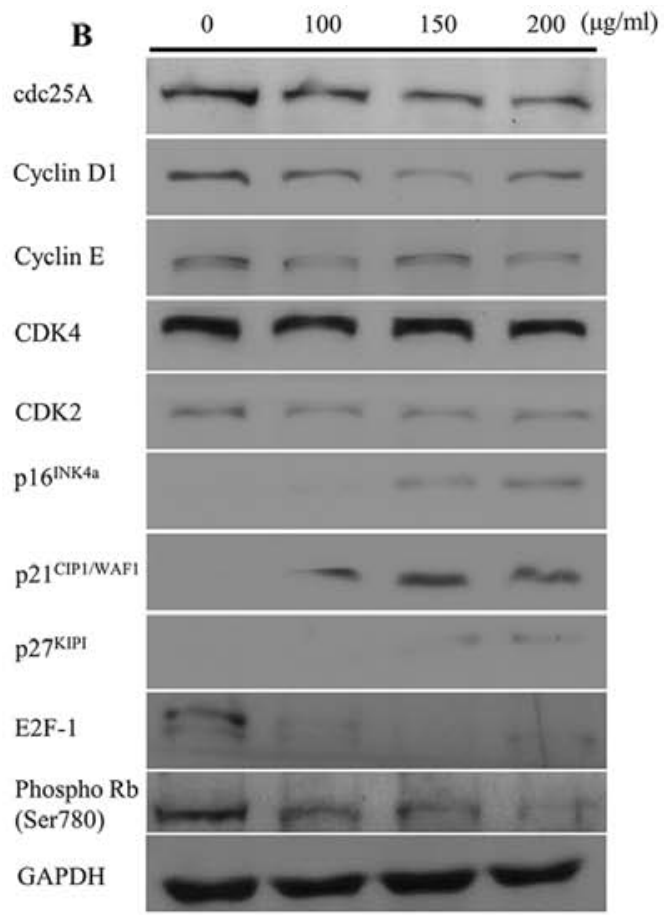

Figure 3. Effects of $C$. amuricus on cell cycle progression of Hep3B cells. (A) Following the treatment with indicated concentrations of the $C$. amuricus extract for $24 \mathrm{~h}$, the ratio (\%) of cell distribution in the indicated stages was analyzed by flow cytometric analysis and compared to non-treated cells. (B) The expression of proteins related to cell cycle was detected by western blot analysis, and GAPDH serves as the loading control. Images show chemiluminescent detection of the blots, which are representative of three independent experiments.

blebbing, cell shrinkage, increased cytoplasm granules and detachment from culture plates (Fig. 1B). The data initially indicate that the extract of $C$. amuricus induces selective cytotoxicity in HCC Hep3B cells.

Effects of C. amuricus on the induction of apoptosis. Further experiments were then carried out to determine whether the extract of $C$. amuricus inhibits the proliferation of Hep3B cells through the induction of apoptosis. Morphological analysis following DAPI staining was examined to analyze the phenotypic changes in the cell nucleus. The classical hallmark of apoptotic cells with chromatin condensation and apoptotic bodies, was observed in Hep3B cells treated with the C. amuricus extract in a dose-dependent manner, indicating that the extract of $C$. amuricus-stimulated Hep3B cell death was a typical apoptotic cell death (Fig. 2A). More evidence 
A

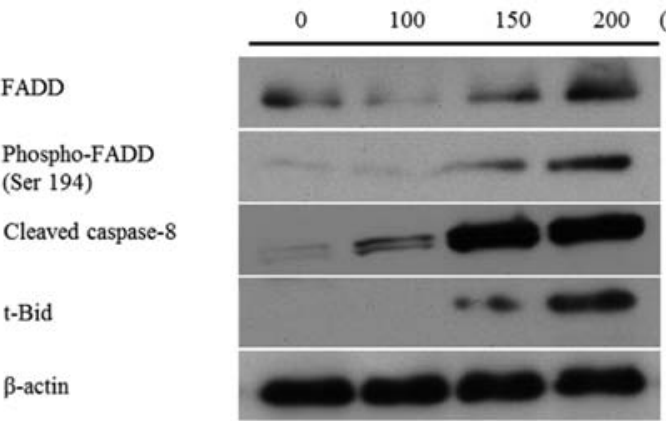

C

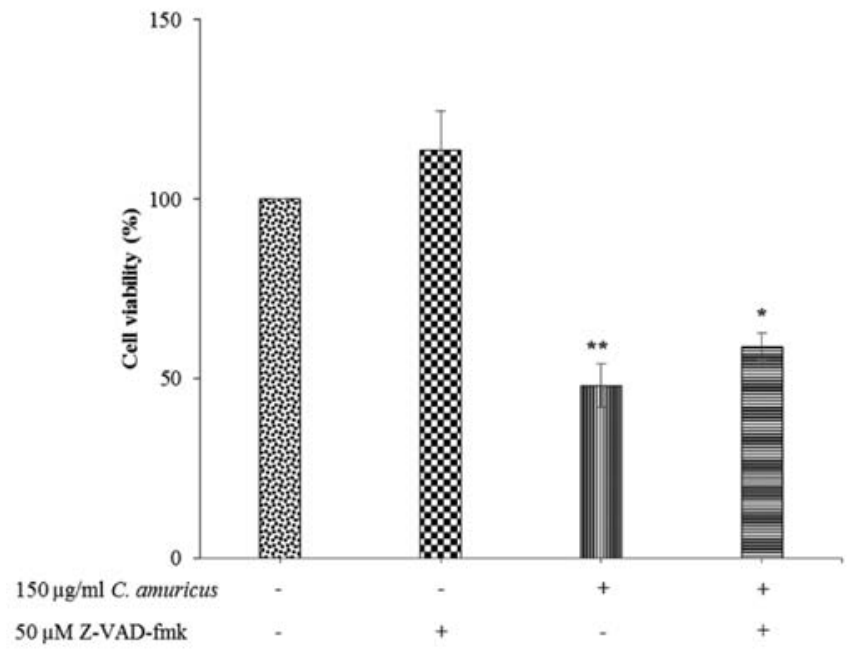

B

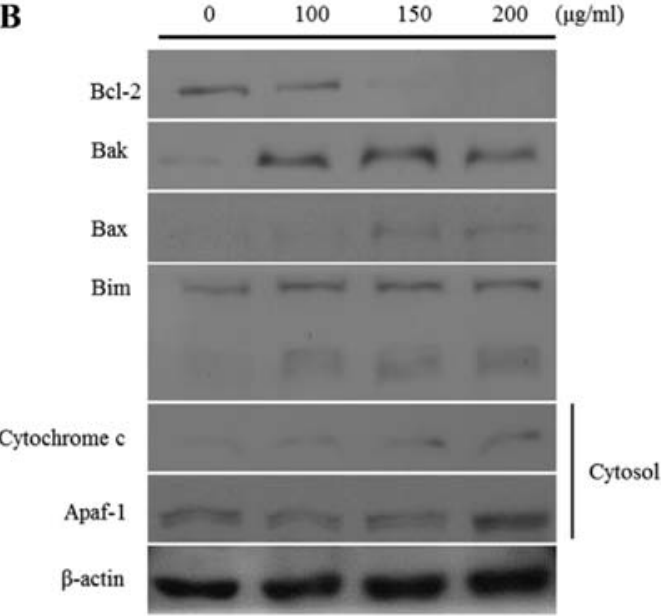

D

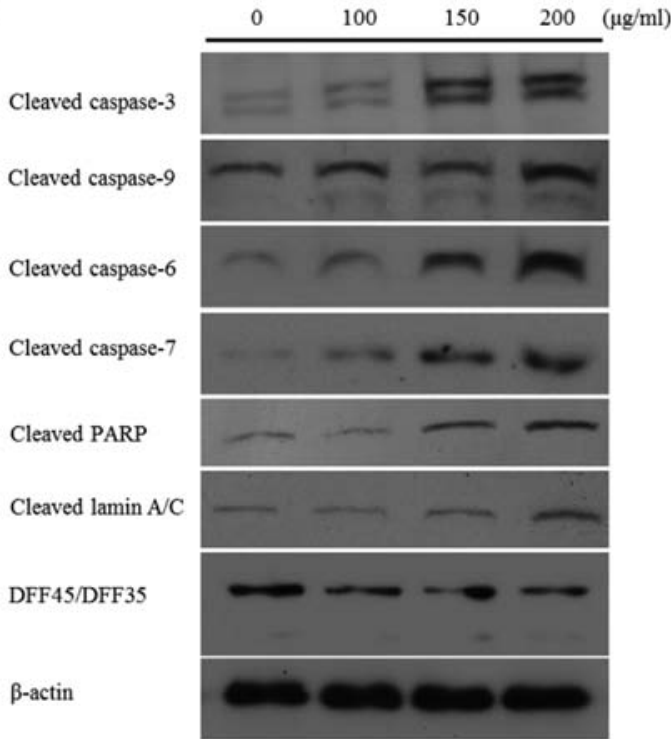

Figure 4. Effects of C. amuricus on the expression of apoptosis-related proteins. The expression of proteins related with extrinsic apoptotic pathway (A), mitochondrial membrane (B) and cleaved form of caspases (D) were detected by western blot analysis in Hep3B cells treated with various concentrations of the $C$. amuricus extract for $24 \mathrm{~h}$, and $\beta$-actin serves as the loading control. Images showed chemiluminescent detection of the blots, which were representative of three independent experiments. (C) Caspase activity assay: the cells were treated with $150 \mu \mathrm{g} / \mathrm{ml}$ of the C. amuricus extract for $24 \mathrm{~h}$ after pre-incubation with Z-VAD-fmk, a caspase inhibitor, for $1 \mathrm{~h}$. Bars represent the mean $\pm \mathrm{SD}$ of three experiments. ${ }^{*} \mathrm{P}<0.05 ;{ }^{* * *} \mathrm{P}<0.01$.

in support of apoptosis was performed by DNA fragmentation assay. The biochemical hallmark of apoptotic cell death, in which cleavage of chromosomal DNA at internucleosomal fragments or multiples at $\sim 180 \mathrm{bp}(13)$, results in a typical DNA electrophoresis ladder, was visible during incubation with the C. amuricus extract (Fig. 2B). On the basis of the above data, the profile for C.amuricus-caused apoptosis closely correlated with its growth suppressive effect. Thus, these phenomena demonstrate that the extract of $C$. amuricus may be considered as an inducer of apoptosis in Hep3B cells.

Effects of C. amuricus on cell cycle distribution. In order to estimate the inhibitory effect of $C$. amuricus on Hep3B cell growth, Hep3B cells were exposed to escalating concentrations of the $C$. amuricus extract and subjected to cell cycle analysis. It could be seen that a $24-\mathrm{h}$ treatment of the $C$. amuricus extract to Hep3B cells caused a definite rise in sub-G1 fractions in a dose-dependent manner. The relative percentages of cells staying at the sub-G1 phase gradually increased from $2.43 \%$ in the non-treated cells to $3.36,8.34$ and $29.84 \%$ in Hep3B cells treated with 100,150 and $200 \mu \mathrm{g} / \mathrm{ml}$ of the C.amuricus extract, respectively (Fig. 3A). As the elevated accumulation of sub-G1 cells exhibits the presence of apoptotic cells, the extract of $C$. amuricus-promoted cell death was concomitant with the growth inhibitory effect. To dissect the biochemical events controlling the transition of cell cycle phases, G1-related proteins subsequently were examined by western blot analysis (Fig. 3B). Downregulation of cdc25A, cyclin D1 and cyclin E, CDK4 and 2, and upregulation of $21^{\mathrm{CIP} / \mathrm{WAF} 1}, \mathrm{p} 27^{\mathrm{KIPI}}$ and p16 $6^{\mathrm{INK} 4 \mathrm{a}}$ were noted in the Hep3B cells following C. amuricus treatment for $24 \mathrm{~h}$. Consistently, the expression of the E2F-1 and phospho- $\mathrm{Rb}$ were lower in the addition of $C$. amuricus. The experimental findings imply that the methanol extract of $C$. amuricus blocks Hep3B cell cycle progression at the sub-G1 phase.

Effects of C. amuricus on the expression of apoptosis-related proteins. The possible molecular mechanisms underlying 


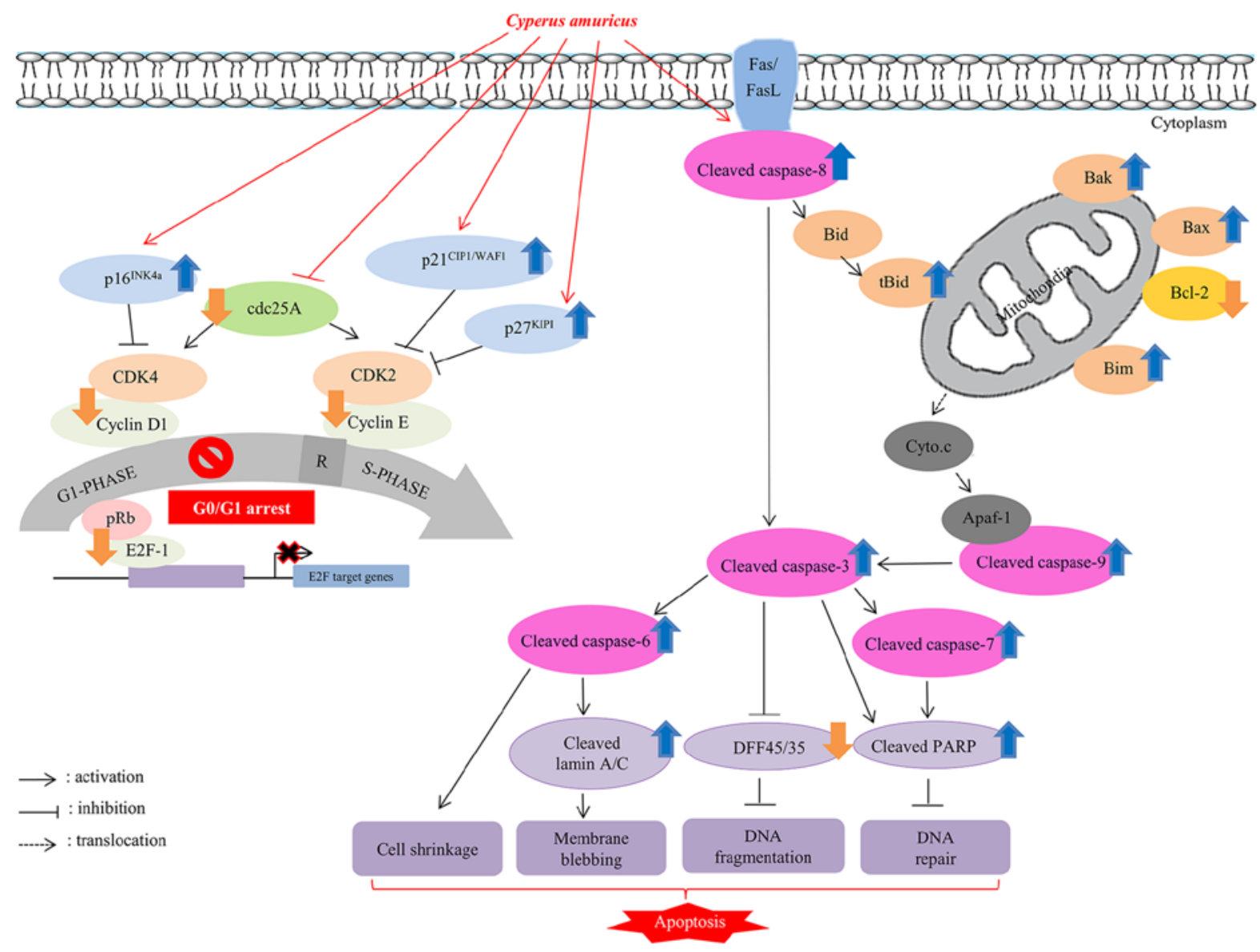

Figure 5. Proposed pathways for the effects of C. amuricus on cell cycle arrest and apoptosis in HCC Hep3B cells.

C. amuricus-induced apoptosis in Hep3B cells were investigated. The effects of $C$. amuricus on the protein expression of Fas-associated death domain (FADD) and phospho-FADD, cleaved caspase- 8 , and truncated Bid (tBid, the active form of Bid) in Hep3B cells were explored. Western blot analysis revealed that $C$. amuricus caused dose-dependent increments in the levels of FADD and phospho-FADD, cleaved caspase- 8 and tBid (Fig. 4A).

The effects of $C$. amuricus on the mitochondria-mediated death pathway regulated by several members of anti- and proapoptotic Bcl-2 family, cytosolic cytochrome $c$ and apoptotic protease activating factor-1 (Apaf-1) were next examined (Fig. 4B). The expression of Bcl-2 was clearly decreased, by way of contrast, the protein levels of Bak, Bax and Bim were notably extended after treatment of Hep3B cells with the C. amuricus extract. Also, a dose-dependent advance in the expression of cytosolic cytochrome $c$ and Apaf-1 was markedly detected in C. amuricus-treated Hep3B cells.

As a first step in identifying whether caspases were involved in the extract of $C$. amuricus-induced apoptosis, Hep3B cells were treated with the caspase inhibitor Z-VAD-fmk. As shown in the results, more cells were alive when treated with Z-VAD-fmk (114\%) and the C. amuricus extract plus Z-VAD-fmk (59\%) than treated with the $C$. amuricus extract alone (48.1\%) (Fig. 4C), suggesting that the extract of C. amuricus is able to affect the activity of caspases. In addition, results of western blot analysis presented the expression of multiple apoptotic proteins, including cleaved caspase-9,
$-3,-7$ and -6 were distinctly higher in response to the extract of $C$. amuricus treatment in a dose-dependent manner. The activation of caspases often lead to the proteolytic cleavage of target proteins poly(ADP ribose) polymerase (PARP), lamins and DNA fragmentation factor DFF45. Under these conditions, cleaved PARP and cleaved lamin A/C protein were expanded gently, while DFF45 was reduced effectively by the treatment with increasing concentrations of the extract of $C$. amuricus (Fig. 4D).

\section{Discussion}

The anticancer activities of natural herbal medicine were thoroughly investigated long ago. Also, their crucial effects on the pathophysiology associated with cancers have recently received special attention, due to many epidemiological reports proposing that several beneficial effects of herbal extracts significantly reduce the risk of many cancers with few side-effects. Although numerous Cyperus species are popularly used in folk medicine and pharmacies as antioxidants and anti-inflammatories, scientific evidence of their effects is essentially required. Therefore, the potential of $C$. amuricus as an anticancer preparation was elucidated in the present study.

The imbalance between cell proliferation and death is considered to be an important event in cancer progression. Among the effects of antitumor reagents, apoptosis and growth inhibition are the most common responses on cancer cells (14). The study demonstrated that the extract of $C$. amuricus 
was significantly toxic towards Hep3B cells, while essentially non-toxic to A549 and HaCaT cells (Fig. 1A). Furthermore, apoptosis is one of the most prevalent pathways through which chemopreventive and/or chemotherapeutic strategies can inhibit the overall growth of cancer cells. Apoptosis involves specific morphological and biochemical changes such as cell shrinkage, chromatin condensation, membrane blebbing, more floating and DNA fragmentation (13). Hence, induction of apoptosis is recognized as a useful indicator for cancer treatment and prevention. Particularly, after $24 \mathrm{~h}$ of treatment with $C$. amuricus extract, marked morphological changes, including the obvious destruction of the monolayer, shrinkage and extensive detachment of cells (Fig. 1B), the increased nuclear chromatin condensation in DAPI staining (Fig. 2A) as well as evident DNA fragmentations (Fig. 2B) were observed, suggesting that $C$. amuricus-induced cell death involves an apoptotic mechanism.

Cancer cells lack normal growth controls, exhibit loss of cell cycle control, have unlimited reproductive potential and have growth-signal self-sufficiency (15). Cell cycle machinery depends on the coordinated activity of protein kinase complexes, each consisting of a cyclin-dependent kinases (CDKs) and cyclins, which act consecutively in G1 to initiate $S$ phase and in G2 to initiate mitosis (16). Progression through G1 phase requires the activities of cyclin D-dependent CDK4 or 6 , followed by activation of the cyclin E- and cyclin A-dependent kinase CDK2. The cyclin-CDK complex formed during G1-phase catalyzes phosphorylation of the dominant inhibitor of G1/S-cell cycle progression, the retinoblastoma Rb family of tumor suppressor proteins, thereby blocking their inhibitory activity allowing the cell to progress into $\mathrm{S}$ phase. The $\mathrm{Rb}$ family proteins bind to members of the E2F transcription factor family and block the E2F-dependent transcription of genes controlling the $\mathrm{G} 1$ to $\mathrm{S}$ phase transition and subsequent DNA synthesis. The phosphorylation of $\mathrm{Rb}$ disrupts its association with E2F, thereby reducing the suppression of E2F target genes and activating the transcription outside G1/S (17). It is also known that these cyclin-CDK complexes often bind to CDK inhibitors (CDKIs), to conduct pivotal functions in cell cycle regulation via the coordination of internal and external signals that inhibit cell cycle progression at critical checkpoints. One group is the INK4 (inhibitors of CDK4) family, which has four members $\mathrm{p} 16^{\mathrm{INK} 4 \mathrm{a}}, \mathrm{p} 15^{\mathrm{INK} 4 \mathrm{~b}}, \mathrm{p} 18^{\mathrm{INK} 4 \mathrm{c}}$ and $\mathrm{p} 19^{\mathrm{INK} 4 \mathrm{~d}}$, all of which share the ability to control the G1/S transition. The second group of CDKIs includes p $21^{\mathrm{CIP1} / \mathrm{WAF} 1}$ and p $27^{\mathrm{KIPI}}$ (18). In the present study, cell cycle analysis exhibited that the extract of C. amuricus has the ability to induce sub-G1 phase arrest in Hep3B cells (Fig. 3A). Another interesting finding is that the concomitant occurrence of apoptosis after $C$. amuricus treatment is mediated with cell cycle arrest in the sub-G1 phase. The increase in sub-G1 phase of $C$. amuricus-treated Hep3B cells may be due to the induction of $S$ phase arrest. Western blot analysis further examined proteins associated with the cell cycle. $C$. amuricus drastically decreased the levels of the protein kinase complexes cdc25A, cyclin D1 and cyclin E, CDK4 and 2 and increased the levels of p16 ${ }^{\mathrm{INK} 4 \mathrm{a}}, \mathrm{p} 21^{\mathrm{CIP} 1 / \mathrm{WAF} 1}$ and $\mathrm{p} 27^{\mathrm{KIPI}}$ proteins in Hep3B cells (Fig. 3B). C. amuricus also induced a reduction in $\mathrm{Rb}$ phosphorylation, then resulted in a contraction of the E2F-1 protein (Fig. 3B). The data indicated that $C$. amuricus elicits cell cycle arrest at sub-G1 phases in
Hep3B cells through the induction of CDKIs and the inhibition of cyclins and CDKs.

Apoptotic pathways include the extrinsic death receptorand intrinsic mitochondria-mediated pathways (19). The extrinsic signaling pathway is related to the membrane death receptors that belong to the tumor necrosis factor (TNF) receptor gene superfamily. To date, the fatty acid synthase ligand/receptor (FasL/FasR) and TNF- $\alpha / T N F R 1$ models are the best characterized ones. The ligation of FasL to FasR results in sequential recruitment of adaptor molecular FADD and a FADD associated procaspase- 8 to the death receptor to form a death-inducing signaling complex (DISC), for execution of cell death (20). Advanced phospho-FADD stimulates binding of caspase- 8 to FADD, leading to cleavage of procaspase- 8 , with the consequent generation of active caspase-8. Active caspase- 8 successively amplifies the apoptotic signal through either direct activation of downstream executioner caspase-3 or cleavage of Bid (19). Bid, a BH3-only pro-apoptotic $\mathrm{Bcl}-2$ family protein, is generally considered as a molecular linker bridging between the death receptor pathway and the mitochondria pathway (21). Uncleaved Bid is predominantly localized in the cytosol as an inactive precursor. Upon cleavage by caspase- 8 , the activated form of $\mathrm{Bid}(\mathrm{tBid})$ migrates to the mitochondria, where it enhances the permeability of the mitochondrial membrane, thus conveys extrinsic apoptotic signals from the cytoplasm to the mitochondria (19). In this study, C. amuricus may trigger caspase- 8 through FADD, and then the activated caspase- 8 cleaved Bid into tBid (Fig. 4A), which was transferred to the mitochondria where it may contribute to the $C$. amuricus-induced activation of the intrinsic apoptotic pathway. Therefore, $C$. amuricus medicated cleavage of Bid in Hep3B cells may be an important event for cross-talk between intrinsic and extrinsic pathways.

The tBid translocates to the mitochondria where it acts with the pro-apoptotic proteins Bax and Bak to initiate the release of pro-apoptotic factors from the mitochondria. The action of Bid and Bax is counteracted by the anti-apoptotic Bcl-2 family members (Bcl-2 and Bcl-xL) which can inhibit mitochondrial pro-apoptotic events. The Bcl-2 family of proteins, located on the outer mitochondrial membrane, is vital in apoptotic modulation by participating in the formation of the pores and altering the mitochondrial permeability (22). The balance between pro-apoptotic (Bid, Bad, Bim, Bax, Bak and Noxa) and anti-apoptotic (Bcl-2, Bcl-xL and Mcl-1) proteins is critical for determining the release into the cytoplasm of many apoptogenic factors (cytochrome $c$ ), to influence cell survival (23). Cytochrome $c$ is a soluble protein located in the mitochondrial intermembrane space, which functions as an electron carrier of the mitochondrial respiration chain between complexes III and IV (24). Once mitochondria senses the cell death stimuli, cytochrome $c$ from the mitochondria can be released into cytosol and binds to Apaf-1, forming the apoptosome-deoxyadenosine triphosphate-dependent complex, which activates caspase-9, and then drives the downstream caspase cascade (caspase-3) and cell death mechanisms. Release of cytochrome $c$ to the cytoplasm is a key step in the initiation of mitochondrial-dependent apoptosis $(24,25)$. Consistent with these findings, $C$. amuricus downregulated the levels of the anti-apoptotic proteins Bcl-2 and upregulated the expression of the pro-apoptotic proteins 
Bak, Bax and Bim in Hep3B cells in a dose-dependent manner. C. amuricus treatment in different doses also promoted the release of cytochrome $c$ and Apaf-1 into the cytosol, which in turn cleaved and activated caspase-9 (Fig. 4B). Collectively, C. amuricus-induced apoptosis of Hep3B cells occurs via the intrinsic mitochondria-mediated pathway, by regulating the expression of the Bcl-2 family proteins, by enhancing the expression of cytosolic cytochrome $c$, Apaf-1, as well as triggering the activation of caspase- 9 and eventually leading to apoptosis.

As a downstream product of cytochrome $c$, caspases are crucial mediators of the principal factors found in apoptotic cells. Among them, caspase- 3 is a frequently activated death protease, catalyzing the specific cleavage of many cellular substrates, most notably PARP. PARP is an enzyme involved in DNA repair, genome surveillance, and genomic integrity maintenance in response to environmental stress; thus, cleaved PARP is regarded as another hallmark of apoptosis (19). The cleavage of PARP induces separation of DNA-binding motifs in $\mathrm{NH} 2$ terminal region of catalytic domains from 116- to 89- and $24 \mathrm{kDa}$, respectively, during drug-induced apoptosis in a variety of cells (26). In the present study, $C$. amuricusinduced cell death distinctly reduced when Hep3B cells were pre-treated with caspase inhibitor Z-VAD-fmk, showing that the activation of caspases is one of the principal mechanisms by which $C$. amuricus extract induces apoptosis (Fig. 4C). The rise of the active (cleaved) forms of caspase-9, caspase-3, caspase-7 and caspase- 6 and cleaved PARP, was further validated in C. amuricus-treated Hep3B cells in a dose-dependent manner. In addition, both the caspase- 3 activation and the subsequent PARP cleavage decreased the expression of DFF45 and increased the expression of lamin A/C after treatment of $C$. amuricus (Fig. 4D). The DFF45 protein is one of the cleavage targets of caspase-3. Activation of caspase-3 triggers the cleavage of DFF45 (or its isoform DFF35), inactivates its inhibitory function on DFF40 and causes nuclear DNA degradation by DFF40, leading to cell death in $C$. amuricus exposure at different doses (27). Another marker cleaved by caspase- 6 by activating caspase- 3 is lamin $\mathrm{A} / \mathrm{C}$, functioning in cell cycle control, DNA replication and nuclear membrane structure and chromatin organization. During apoptosis, lamin $\mathrm{A} / \mathrm{C}$ is specifically cleaved into large $(41-50 \mathrm{kDa})$ and small (28 kDa) fragments (28), and the cleavage of lamin A/C results in nuclear dysregulation and cell death. Results indicated that C. amuricus activates caspase-3 and it cleaves specific target proteins committing Hep3B cells to apoptosis. The activation of caspases principally amplifies apoptotic signaling via two distinct pathways: the extrinsic-death receptor pathway and the intrinsic mitochondrial pathway. In the present study, the activation of the intrinsic mitochondrial pathway is involved in the permeabilization of the outer mitochondrial membrane with subsequent releases of pro-apoptotic factors, including cytochrome $c$, into the cytosol. Cytosolic cytochrome $c$ alters the conformation of the cytosolic protein Apaf-1, whereas this protein oligomerizes with inactive procaspase-9, resulting in the activation of this enzyme. Additionally, the cleavage and activation of the initiator caspase- 8 and -9 occurred after C. amuricus exposure. This, in turn, leads to the activation of executioner caspase-3, -6 and -7 , ending with the cleavage of several intracellular polypeptides (PARP-1, DFF45 and lamin A/C) as well as DNA fragmentation, which provokes the induction of apoptosis (27).

In conclusion, a wide range of anticancer effects of C. amuricus methanol extract such as cell cycle arrest and apoptosis on Hep3B cells, a representative p53-null HCC that contains copies of hepatitis B virus (HBV) genomes in their chromosomes, and actively secrets HBsAg (29), is illustrated in Fig. 5. This study, therefore, extends the understanding on the molecular mechanisms underlying the diverse anticancer activities of $C$. amuricus on human liver cancer. However, further studies in animal models are needed to validate the usefulness of this strategy in vivo. It could be informative to elucidate the precise mechanism and biological efficacy of this medicinal herb on biological cellular response in other cancer types to chemo-sensitization.

\section{Acknowledgements}

The present study was supported by a research grant from the Pukyong National University in year 2016.

\section{References}

1. Llovet JM, Burroughs A and Bruix J: Hepatocellular carcinoma. Lancet 362: 1907-1917, 2003.

2. Ferlay J, Shin HR, Bray F, Forman D, Mathers C and Parkin DM: Estimates of worldwide burden of cancer in 2008: GLOBOCAN 2008. Int J Cancer 127: 2893-2917, 2010.

3. Rampone B, Schiavone B, Martino A, Viviano C and Confuorto G: Current management strategy of hepatocellular carcinoma. World J Gastroenterol 15: 3210-3216, 2009.

4. Anthony PP: Hepatocellular carcinoma: An overview. Histopathology 39: 109-118, 2001.

5. Sandal T: Molecular aspects of the mammalian cell cycle and cancer. Oncologist 7: 73-81, 2002.

6. Kögel D, Fulda S and Mittelbronn M: Therapeutic exploitation of apoptosis and autophagy for glioblastoma. Anticancer Agents Med Chem 10: 438-449, 2010.

7. Sofowora A, Ogunbodede E and Onayade A: The role and place of medicinal plants in the strategies for disease prevention. Afr J Tradit Complement Altern Med 10: 210-229, 2013.

8. Maximowicz and Mém: Acad. Imp. Sci. St.-Pétersbourg Divers Savans 9. Prim. Fl. Amur. 296, 1859.

9. Kakarla L, Allu PR, Rama C and Botlagunta M: A review on biological and chemical properties of Cyperus species. Res J Pharm Biol Chem Sci 5: 1142-1155, 2014.

10. Rahmatullah M, Ferdausi D, Mollik AH, Jahan R, Chowdhury MH and Haque WM: A survey of medicinal plants used by Kavirajes of Chalna area, Khulna district, Bangladesh. Afr J Tradit Complement Altern Med 7: 91-97, 2009.

11. Lee SI, Choi H, Jeon H, Baek NI, Kim SH, Kim HJ, Cho CH, Ahn HC, Yang JH, Chae BS, et al: Antioxidant phenolic components from the whole plant extract of Cyperus amuricus Max. Korean J Pharmacogn 39: 233-236, 2008.

12. Sharma N, Sharma VK and Seo SY: Screening of some medicinal plants for anti-lipase activity. J Ethnopharmacol 97: 453-456, 2005.

13. Nicholson DW and Thornberry NA: Caspases: Killer proteases. Trends Biochem Sci 22: 299-306, 1997.

14. Ayed-Boussema I, Bouaziz C, Rjiba K, Valenti K, Laporte F, Bacha $\mathrm{H}$ and Hassen W: The mycotoxin Zearalenone induces apoptosis in human hepatocytes (HepG2) via p53-dependent mitochondrial signaling pathway. Toxicol In Vitro 22: 1671-1680, 2008.

15. Hartwell LH and Kastan MB: Cell cycle control and cancer. Science 266: 1821-1828, 1994.

16. Morgan DO: Cyclin-dependent kinases: Engines, clocks, and microprocessors. Annu Rev Cell Dev Biol 13: 261-291, 1997.

17. Knudsen ES and Knudsen KE: Tailoring to RB: Tumour suppressor status and therapeutic response. Nat Rev Cancer 8: 714-724, 2008. 
18. Li W, Sanki A, Karim RZ, Thompson JF, Soon Lee C, Zhuang L, McCarthy SW and Scolyer RA: The role of cell cycle regulatory proteins in the pathogenesis of melanoma. Pathology 38: 287-301, 2006

19. Jin Z and El-Deiry WS: Overview of cell death signaling pathways. Cancer Biol Ther 4: 139-163, 2005.

20. Wang $\mathrm{H}$, Ao M, Wu J and Yu L: TNF $\alpha$ and Fas/FasL pathways are involved in 9-Methoxycamptothecin-induced apoptosis in cancer cells with oxidative stress and $\mathrm{G} 2 / \mathrm{M}$ cell cycle arrest. Food Chem Toxicol 55: 396-410, 2013.

21. Breckenridge DG and Xue D: Regulation of mitochondrial membrane permeabilization by BCL-2 family proteins and caspases. Curr Opin Cell Biol 16: 647-652, 2004.

22. Portt L, Norman G, Clapp C, Greenwood M and Greenwood MT: Anti-apoptosis and cell survival: A review. Biochim Biophys Acta 1813: 238-259, 2011.

23. Leibowitz B and Yu J: Mitochondrial signaling in cell death via the Bcl-2 family. Cancer Biol Ther 9: 417-422, 2010.

24. Abu-Qare AW and Abou-Donia MB: Biomarkers of apoptosis: Release of cytochrome c, activation of caspase-3, induction of 8-hydroxy-2'-deoxyguanosine, increased 3-nitrotyrosine, and alteration of p53 gene. J Toxicol Environ Health B Crit Rev 4: 313-332, 2001.
25. Green DR: Apoptotic pathways: Ten minutes to dead. Cell 121: 671-674, 2005.

26. Boulares AH, Yakovlev AG, Ivanova V, Stoica BA, Wang G, Iyer S and Smulson M: Role of poly(ADP-ribose) polymerase (PARP) cleavage in apoptosis. Caspase 3-resistant PARP mutant increases rates of apoptosis in transfected cells. J Biol Chem 274: 22932-22940, 1999.

27. Ozören N and El-Deiry WS: Cell surface death receptor signaling in normal and cancer cells. Semin Cancer Biol 13: $135-147,2003$.

28. Lazebnik YA, Takahashi A, Moir RD, Goldman RD, Poirier GG, Kaufmann SH and Earnshaw WC: Studies of the lamin proteinase reveal multiple parallel biochemical pathways during apoptotic execution. Proc Natl Acad Sci USA 92: 9042-9046, 1995.

29. Twist EM, Clark HF, Aden DP, Knowles BB and Plotkin SA: Integration pattern of hepatitis B virus DNA sequences in human hepatoma cell lines. J Virol 37: 239-243, 1981. 